\title{
The Digital Dreamtime: A Shining Light in the Culture War
}

\section{Introduction}

Light is meaningful only in relation to darkness, and truth presupposes error. It is these mingled opposites which people our life, which make it pungent, intoxicating. We only exist in terms of conflict, in the zone where black and white clash.

\section{Louis Aragon 1}

The realm of the arts is often viewed as the stronghold in the last line of defence against the enduring colonisation process of the minority Aboriginal populace. It is one of few avenues in Australian society where Aboriginal people can have a voice and fortunately this is partly driven by the influence of the outside international artworld. In more recent years the digital production areas have further enabled the space and recognition for self-determined, culturally specific and diverse sources of creativity, exchange and community building. This is all despite a culture war where mainstream institutions such as the galleries sector, the associated funding bodies, academia and the media are all being utilised and strengthened as non-military mechanisms of imperialism.

The culture war, or history wars, has mostly been enacted in the mainstream society through the media and the academy. Also at issue is establishing whose definition of Australia will dominate? and on what basic historical precepts? That is, was Australia invaded or settled? Were there massacres or not? Were the children taken away or not? Which society is more immoral? Under John Howards prime minister-ship (1996 - 2007), those whose scholarship mentioned the words invasion, massacres and forced removal as truths of Australian history were labelled Black Armband historians. Others mobilised to decry any negativity towards Australia and Australian history. Subsequently, views contrary 
to the neo-liberal version began to find themselves further marginalised. Including if those views were communicated through the arts and particularly if the artists were Aboriginal.

Works by Aboriginal artists are rarely, if ever, included in mainstream Australian New Media Arts exhibitions or events, and likewise, there are very few Aboriginal curators who include Aboriginal New Media Arts in their exhibitions, so by default there is a huge divergence. This is a curious position because the exclusion or separatism would barely be tolerated in exhibitions that represent a more popular artform, like painting for example. There would be a huge outcry because Aboriginal Art is quite prominent internationally, especially in contrast to Australian Art. It seems that Aboriginal people are expected to assimilate and give up general cultural and social practices, however, artistically the expectation is the reverse keep those nice ancient artworks coming!

Over the past decade or so, part of the 'New Media problem' was explained away with excuses relating to expense, lack of staff expertise and limited access to technology. Of course, over time the technical issues have changed, but not the attitudes in the industry. There is also the problem of cultural jealousy or entitlement issues from non-Indigenous artist colleagues that creates a kind of lateral violence, from artist to artist. A young Chinese Curator recently publicly admitted this by stating "Moreover, the success of the Indigenous art industry in the Northern Territory means non-Aboriginal artists often feel neglected" about the issues inherent in her exhibition of local artists who have resided in Darwin, titled 'Territory Time'.2 It really must be said that the resistance to inclusive attitudes towards Aboriginal artists can only be attributed as institutional racism. As Greg Tate has written "No area of intellectual life has been more resistant to recognising and authorizing people of color than the world of the "serious" visual arts. To this day it remains a bastion of white supremacy..."3

However, it isn't only Aboriginal culture that has been silenced by the actions of John Howards' government. When the Australia Councils' New Media Arts Board was disbanded for political reasons, it left a huge gap for mainstream, or nonIndigenous New Media Arts. Since then the board has been renamed "Inter-Arts", after the Canada Council namesake. Now only guest peer assessors are engaged, instead of having board members over a term of $1-3$ years, so essentially the brains trust of the board has been lost and so has the 
relationship to some of the Aboriginal Artists that felt confident and persistent enough to apply. From where I sit as an artist who has had first hand experience with funding body boards, I find it unfortunate that no other Australia Council board has taken up the slack and bothered to really engage peers with New Media expertise, or effectively implemented initiatives with a New Media focus. Altho107ugh, the other artform boards have gladly accepted the funding that was disseminated for New Media projects. The most recent paradox being that the Australia Councils 2011 roadshow propaganda imparted a lip service focus on the strategic priorities of "Artistic Innovation", "Arts Content in the Digital Era" and "Indigenous involvement". 4

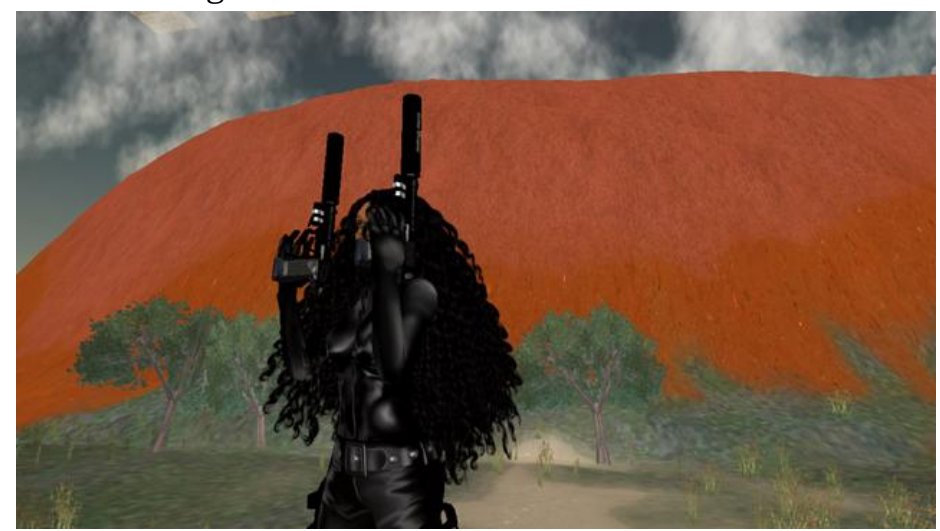

image: Aroha Groves, 'Whats a blakfella doing in a Virtual Realm', Machinima, Dimensions Variable

Trans Media, Inter-Art or Interdisciplinary Artwork specifically describes a process that engages more than one single art form, either between different art forms or collaborations involving cultural and artistic differences. 'Burning Daylight' is a recent example of a large-scale interdisciplinary new media production which is devised and performed by the Marrugeku Company, physical theatre practitioners from the Stalker Theatre Company and also featuring local talent in Broome, a remote coastal town in the far north-west Kimberley region.

Incorporating contemporary dance, film, live music and karaoke, the project combines the unique performance style of Western Australian Indigenous dancers and musicians with 
Malaysian martial arts, unique Japanese and Chinese influences, and the company's visual and acrobatic performance language. A series of happening dance scenes unfold highlighting the friction, local humour and cultural collision in the streets at night in the part of Broome known as "The Bronx". The karaoke videos envelope the onstage performers with historic Broome characters... such as the pearl diver, geisha and the Aboriginal cowboy. Although on tour now, this kind of production is rarely seen in Australia, due to the lack of funding and support for such large-scale events, but is featured in many international festivals for large arts-friendly audiences.

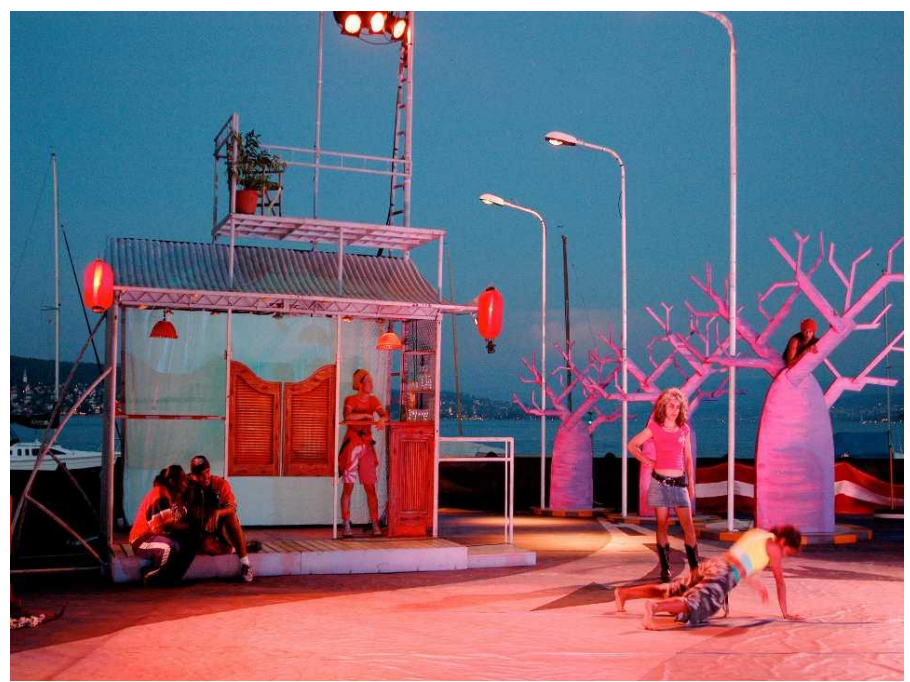

image: Burning Daylight, Marrugeku Company 2009

A few of the artists that have invested a great deal of energy into crafting a practice and also in developing a movement of Aboriginal New Media Arts in Australia are r e a, Jason Davidson and myself and sometimes we present works under the name of the Blackout Collective. Because we also work in a variety of disciplines and come from diverse backgrounds we have achieved some groundbreaking works. Each of our works comment on our own Aboriginal experience while establishing a niche and maintaining our own unique style. Our works are also often more appreciated internationally than in Australia, yet none of us have received 
project funding from any Australia Council artform board since the disbanding of the New Media Arts Board in 2004.

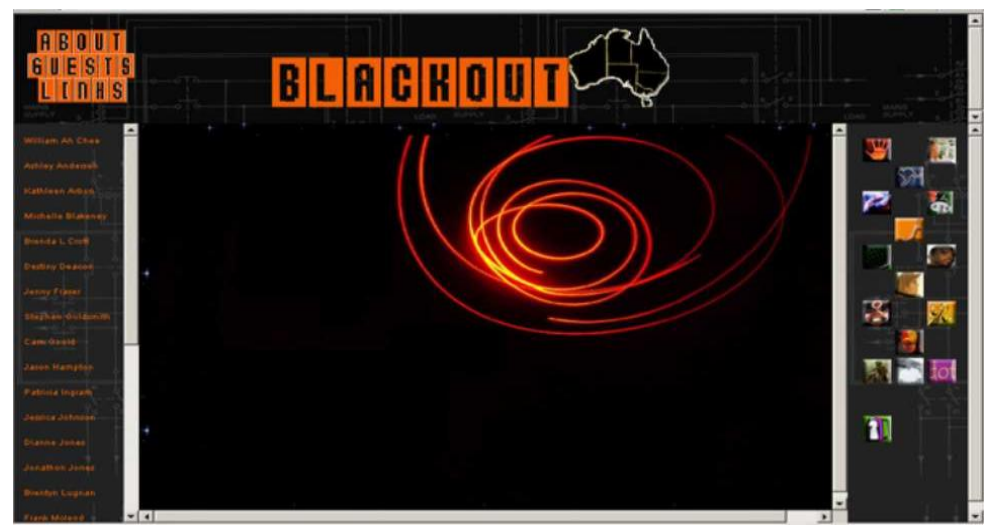

Image: the blackout collective website circa 2003

$\mathrm{r}$ e a is a Gamilaraay/Wailwan artist, originally from Coonabarabran, a remote town in New South Wales, but is a long-time Sydney resident. She has a background in electronics in her mainstream employment and went on to study photography at the College of Fine Arts in Sydney and other courses at post-graduate level including Digital Imaging and Design at New York University. She has a "long" history in the New Media Arts scene and her current practice mainly involves video and digital imaging processes.

Her recent work 'maang (messagestick)' is a three channel video and sound installation featuring historical $16 \mathrm{~mm}$ black and white film excerpts originally made by William Grayden during his expedition, with Pastor Doug Nichols. The ABC TV show Time Frame, described this footage as "remains today a powerful expose of the conditions suffered by some of the Pitjantjatjara Aboriginal people who had been displaced by the 1956 Maralinga atomic bomb tests." 5 The tests were ordered by the British and carried out by Australians, it lasted for ten years, The Pitjantjatjara people were forced from their native land, they had then been hit by serious drought. Seeking water, food and medical attention, they had struggled across hundreds of kilometres of outback terrain to reach the Warburton Mission. There the camera documented the terrible results of sun exposure, thirst and starvation, trachoma and blindness. 
Maang (messagestick) was shown at Planet Indigenus in Toronto 2009, the 2007 Auckland Triennial and was also toured Asia in the International Digital Art Project 'Vernacular Terrain 2' exhibition which featured Australian Aboriginal artists for the first time in 2008.

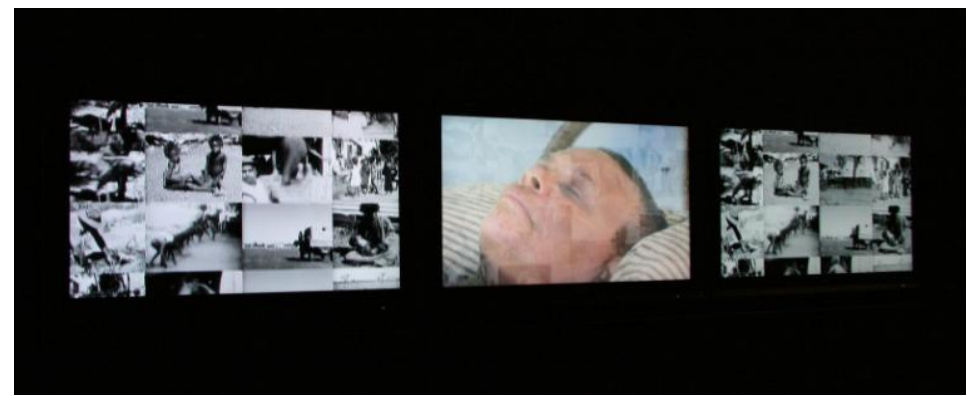

image: $r$ e a, detail from maang (messagestick) 2006-07, Three channel DVD \& sound installation, Dimensions Variable

Jason Davidson a Gurindji/Mara/Nalakarn artist, currently based in Canberra, has a background in music and design. He studied Visual Arts at Charles Darwin University in the Northern Territory. His practice involves producing works including elements of animation, video, music and his unique 'X-Ray' art style - hand drawn designs of animals and body organs. Jasons work, 'Street Machine' explores ideas about masculinity and health - the car as a body and incorporates his signature $\mathrm{x}$-ray art/sci-fi style digital designs.

He said of the work "This project is about looking at ways to break the white mans magic spell. This is a small part of my story a message back for the community, a message about hope, its there, you cant see but maybe you can feel it and maybe sometimes hope has a way to find and call all those once were warriors who been reduced to dust." 6 A project that is already seven years in the making, he produced the work coinciding with his research in Cross-Cultural Communication Breakdown as a part of his Masters of Health degree at the Tropical Health Institute.

Very recently he has brought these issues to light again with the launch of a new website Aboriginal Imagination. Featuring the arts, health and copyright, the website is also intended as a safe haven for family members and other artists to promote their artwork in an Aboriginal controlled environment free of other cultural gate-keepers. 


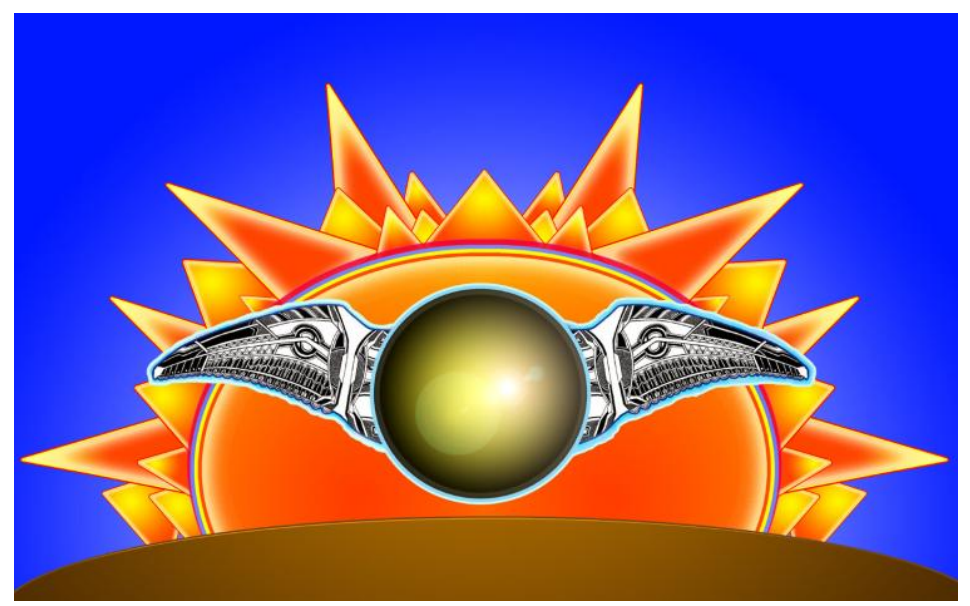

image: Jason Davidson, 'Falcon Wings for Hope' detail from 'Street Machine', 2010.

With a background in education, my art practice to date has involved developing a screen-based practice, curating exhibitions and maintaining a long-term online gallery presence. I am a Murri and studied through the Queensland University of Technology in Brisbane, and am currently based between there and Darwin in the Northern Territory.

Recent work 'Indian Cowboys / Cowboy Indians' is a communication to my old people. When pondering their image, I noticed that the photographs had been doctored to lighten them. This pains me. It seems that they were too black. They worked on cattle properties, far away from their homelands. I wish to try to let them know what their old stomping ground is like now... dressing-up in the photo booth is something that people do for fun on our home-lands. It's not real, but it is the photography of the day in a theme park inspired playground. Pictured here is my art family, lenticular-style, a movement, a resistance... I am left to wonder how real the portrait sittings were for my old people? Did they find it fun? Given a choice, how would they dress now? Would they choose the Indian or the Cowboy or the Cowboy Indian? The work was recently shown at ICAN the Indonesian Contemporary Art Network in Jogjakarta. 


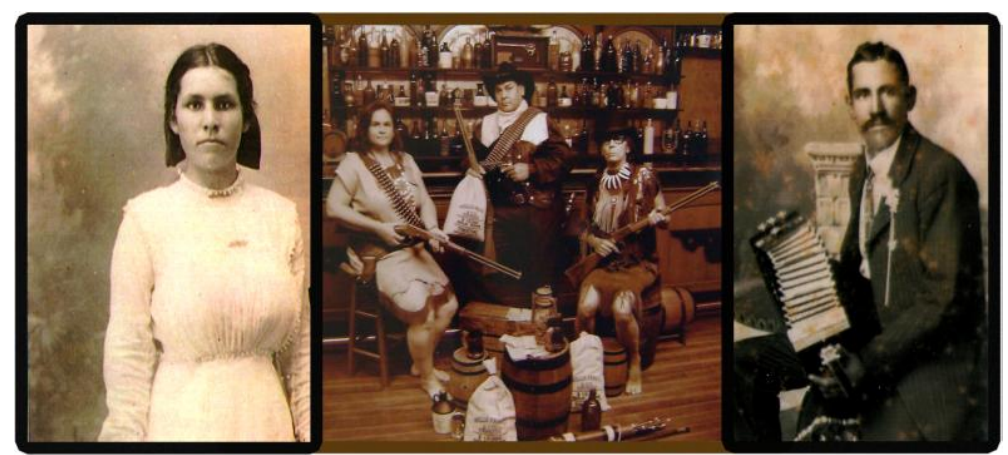

Slide: Jenny Fraser, detail from 'Indian Cowboys / Cowboy Indians', Video Installation, 2009

As Martin Luther King Junior has said "Returning hate for hate multiplies hate, adding deeper darkness to a night already devoid of stars. Darkness cannot drive out darkness: only light can do that. Hate cannot drive out hate: only love can do that." 7 Therefore my personal contribution to culture and sharing the love for over a decade has included founding and maintaining cyberTribe - an online art gallery that features the works of Indigenous Artists internationally. With a regular program of exhibitions both online and in other gallery spaces, it fills a much needed space, in order to appreciate the work of those labelled as "Urban Artists" producing conceptual / new media / contemporary artwork alongside those innovating in traditional or customary practices and to comment on individual and collective Aboriginal experiences. 

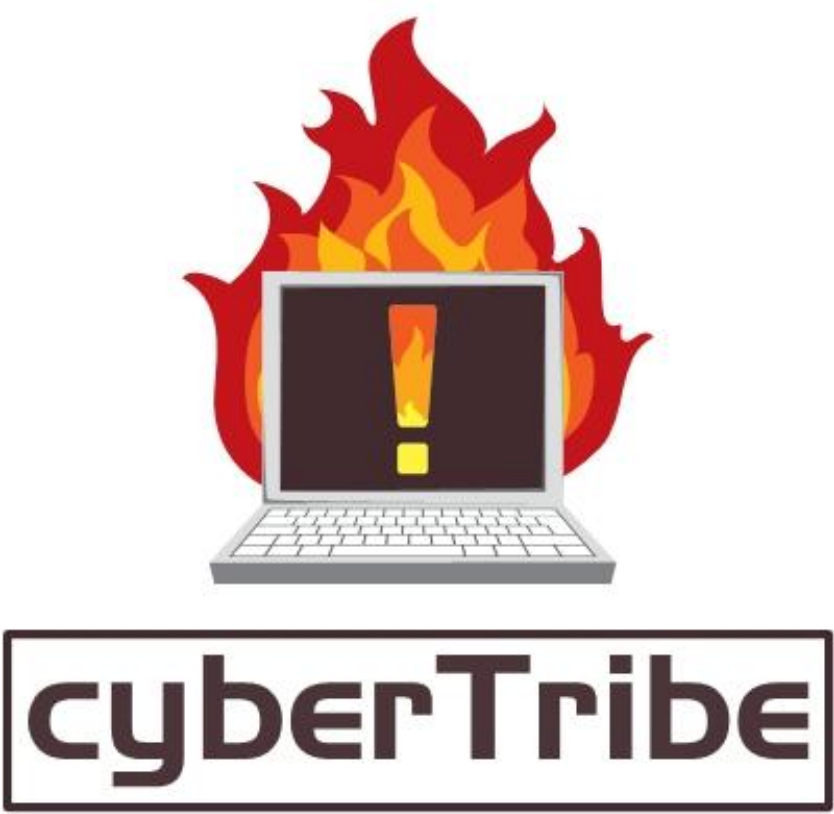

image: cyberTribe logo circa 2010

Any Indigenous presence in the world of Indigenous Arts provides new perspectives for audiences and perhaps encourages more inclusion of Indigenous Art in the mainstream exhibitions and events, where this is often overlooked or subject to cultural gate-keeping. Many digital productions include participation by Indigenous people and contributes to individual and community empowerment. These images and initiatives produced under the idea of selfrepresentation can then talk back to the dominant images as a matter of conflict between alternative readings of society. Institutional acceptance of this requires true leadership and the challenge of genuine discourse. 


\section{References}

1. Aragon, L. (1926) Paris Peasant, "Preface to a Modern Mythology".

2. Zhou, S. (2011) Chan Contemporary Art Space Interview. Off The Leash, p 16, July

3. Tate, G. (1989) 'Nobody Loves a Genius Child', Village Voice (November 14)

4. Christie, L. (2011) 'Darwin Funding Forum Presentation', Australia Council website as at June 30:

http://www.australiacouncil.gov.au/_data/assets/pdf_file/0011 1102026/Darwin_Funding_Forum presentation for attendees.pdf

5. Time Frame (1997) '1967...Citizens At Last?' ABC TV Show, Episode 5; Online Archive:

http://www.abc.net.au/time/episodes/ep5.htm

6. Hall, S. (1980) 'Fetishism in film "Theory" and "Practice"', Australian Journal of Screen Theory, 5 and 6. pp.48-66.

7. Davidson, J. (2010) Email conversation, September 24, 2010

\section{Other related links:}

Blackout Collective - http://www.cybertribe.culture2.org/blackout

Marrugeku Company - 'Burning Daylight' -

http://www.marrugeku.com.au/burningdaylight

Jason Davidson - 'Street Machine' -

http://www.aboriginalimagination.com.au/projects.html

r e a - http://www.breenspace.com/artists/21/exhibitions/r-e-a

Jenny Fraser - http://www.cybertribe.culture2.org/jennyfraser

cyberTribe - http://www.cybertribe.culture2.org

Aroha Groves - video: a walkthrough of 'Connections2' -

http://www.youtube.com/sistagrlro 